\title{
Design of Breast Model using Different Dielectric Materials and UWB Antenna for Tumor Detection
}

\author{
Harshal Nigam, Monika Mathur, Mukesh Arora \\ Department of Electronics and Communication Engineering, Swami Keshvanand Institute of Technology, \\ Management \& Gramothan, Jaipur, Rajasthan (INDIA) \\ Email : hrshlnigam@gmail.com, monikamathur16@gmail.com \\ Received 13.02.2021, Received in revised form 18.03.2021, Accepted 04.04.2021
}

\begin{abstract}
A breast model has been proposed in this paper. The model is designed on CST Microwave studio. The outer layer is skin, then fat layer and then breast tissue layer is made of different dielectric constant materials. The tumor is taken as a sphere which is placed inside the breast at different positions for detection purpose. A novel antenna to detect breast cancer tumor is also proposed in this paper. The UWB antenna is designed in the frequency range 3.3-10.6 GHz. The antenna shows a return loss $\mathrm{S11}$ less than $10 \mathrm{~dB}$ for the UWB frequency range and a maximum gain of $3.49 \mathrm{~dB}$ in this range. The designed UWB antennas can be placed on both sides of breast model such that the signal scattered by the breast tumor can be detected by the receiving antenna. The overall size of antenna is $20 \times 30 \mathrm{~mm}^{2}$ and designed on FR4 substrate
\end{abstract}

Keywords: Breast cancer, Tumor Cells, Microstrip Antenna, UWB, Cancer Detection

\section{INTRODUCTION}

In 2018, by cancer research UK around, 17 million cancer cases were reported among them the major cancer were due to breast cancer, lung cancer and prostate cancer, this number is expected to be about 27.5 million by 2040. [1]

The breast cancer is mainly detected in woman of age group 25-40 so it is expected to detect the breast cancer initially so that it can be treated. [2-4]

The wireless systems having antenna are very much used for detection of breast cancer. There are many topologies of antenna systems that can be used for tumor inside breasts [5-6]

FCC has allocated a bandwidth of $3.1-10.6 \mathrm{GHz}$ for commercial applications of Ultra-wide band. UWB systems have a higher bandwidth which points towards pulses of very small time duration, thus UWB pulses can be used for biomedical applications for visualization of tumor inside body without any destruction. [7-8]

The detection of tumor inside the breast can be detected by techniques such as MBI (Microwave breast imaging) [9-10]

The MBI technique involves the use of transmitter and receiver antennas and the transmitted signals from antenna are scattered due to the presence of tumor as detected by received antenna and presence of tumor can be detected, to illustrate this technique first of all a breast model mimicking a real breast with skin, fat layer and breast tissues is modelled on the software and then keeping the antennas on both sides, the model is simulated. [11]

In this paper, first of all a UWB antenna is designed showing good return loss characteristics and a proper gain. The breast model is next designed on CST Microwave studio having different layers with proper dielectric properties so as to mimic a real breast. The tumor having a very high dielectric constant is also placed in the model. The future work will be to place the antennas on two sides of the model and to detect the presence of tumor for different positions and size of the tumor.

\section{UWB ANTENNA DESIGN}

The patch antenna has been designed to work on UWB frequency range as shown in Fig.1. The design has been simulated on FR4 substrate having dielectric constant of 4.4 and a thickness of $1.6 \mathrm{~mm}$. The front view of the antenna is as shown in Fig. 1(a). The dimensions in $\mathrm{mm}$ are as given in Table 1. The back view is as shown in Fig. 1(b) where there is a partial ground plane to obtain UWB characteristics.

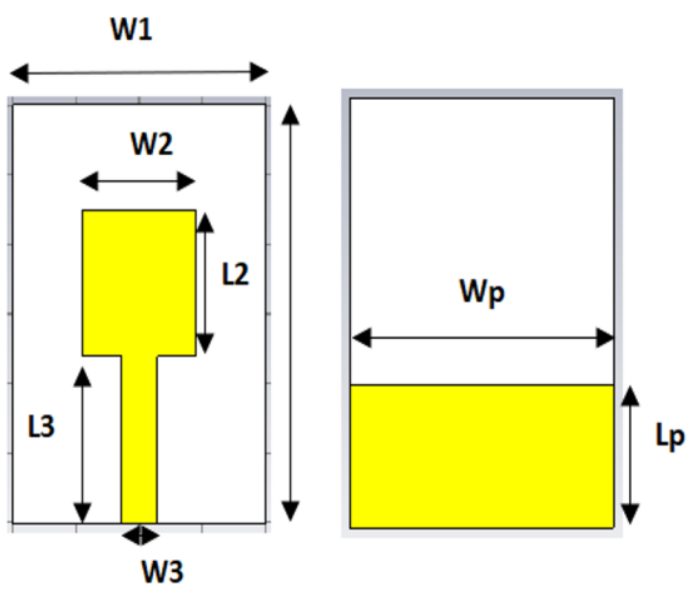

Fig.1 Front and back view of Antenna 
The designed antenna is simulated on CST Microwave studio and it was observed that $\mathrm{S} 11(\mathrm{~dB})$ return loss was less than $-10 \mathrm{~dB}$ for UWB frequency range. The minimum return loss in the UWB range is observed at a frequency of $9.344 \mathrm{GHz}$. As seen in Fig. 2.

Table 1. Dimensions of Antenna (mm)

\begin{tabular}{|c|c|c|c|}
\hline W1 & 20 & L1 & 30 \\
\hline W2 & 9 & L2 & 10.5 \\
\hline W3 & 2.9 & L3 & 12 \\
\hline Wp & 20 & Lp & 10 \\
\hline
\end{tabular}

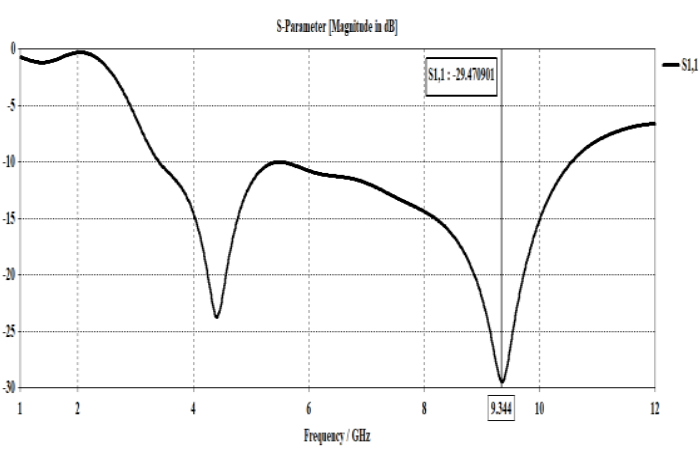

Fig.2. S11 vs frequency plot

The plot for gain is also simulated with frequency as in Fig. 3, it can be seen that a peak gain of 3.49 $\mathrm{dB}$ can be obtained at a frequency of $7.3 \mathrm{GHz}$ in the UWB range.

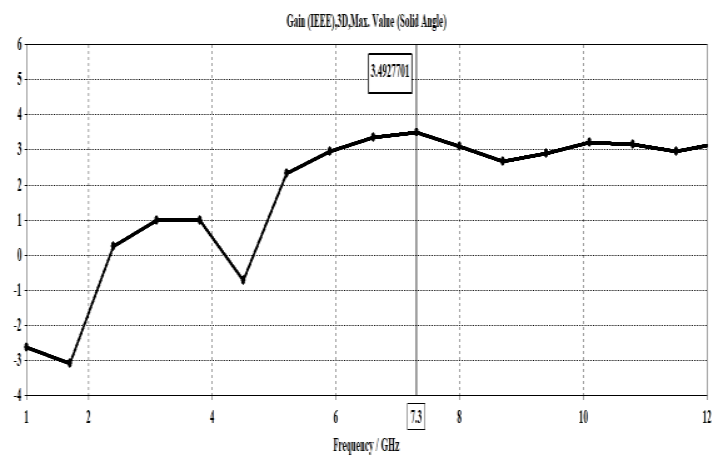

Fig.3 Gain vs Frequency plot

\section{BREAST MODEL DESIGN}

A breast model in conical form is also designed as shown in Fig.4. The model represents different layers of the breast including skin layer, fat layer, breast tissues and the presence of tumor. The above designed antennas can be placed on both sides of this model as a future work to detect the presence of tumor. The tumor position in the model can be varied along with the variation of the radius of the tumor.

The permittivity and conductivity for different layers of breast is also shown in Table 2. It can be observed that tumor has a very high dielectric which scatters the transmitted signal, so the pattern of received signal changes and tumor can be detected.

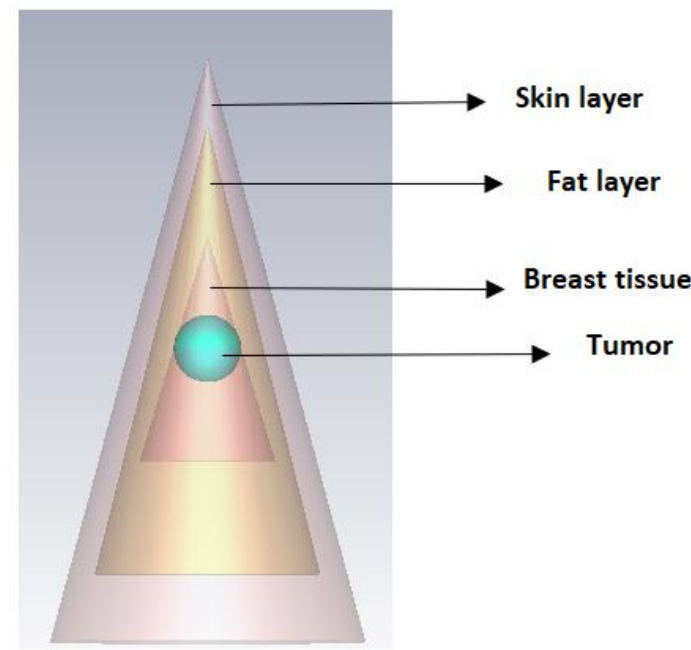

Fig.4. Breast model

Table 2. Permittivity and Conductivity of different layers

\begin{tabular}{|c|c|c|}
\hline Material & Permittivity $(\square \mathbf{r})$ & $\begin{array}{c}\text { Conductivity } \\
(\mathbf{S} / \mathbf{m})\end{array}$ \\
\hline Skin & 38 & 1.46 \\
\hline Fat & 5.28 & 0.1 \\
\hline Breast tissue & 4.49 & 0.59 \\
\hline Tumor & 50 & 4 \\
\hline
\end{tabular}

\section{CONCLUSION}

This paper depicts the design of a UWB antenna for tumor detection. The antenna is of small size and operated on UWB band that can be used for biomedical applications, apart from this a model of breast is also designed for detection. This model has got different layers as in a real breast and this can be used for future detection of tumor inside the breast.

\section{REFERENCES}

[1] Cancer Research UK.

https://www.cancerresearchuk.org/health-

professional/cancer-statistics/worldwidecancer 2019

[2] Rabia Caliskan, S., Gultekin, S., Uzer, D. and Dundar, O. (2015) A Microstrip Patch Antenna Design for Breast Cancer Detection. Procedia -Social and Behavioral Science 195,2905-2911,2015

[3] Yu, Z.G., Jia, C.X., Geng, C.Z., Tang, J.H., Zhang, J. and Liu, L.Y. (2012) Risk Factors Related to Female Breast Cancer in Regions of Northeast China: A 1:3 Matched Case-Control Population-Based Study. Chinese Medical Journal , 125, 733-740.

[4] Globocan (2004) Cancer Incidence, Mortality and Prevalence Worldwide. IARC Cancer Base No. 5. Version 2.0, IARC Press, Lyon. Miyakawa, M., Ishida, T. and Watanabe, M. (2004)

[5] Aman Nag, Divesh mittal, Avneet Kaur, "THz Rectangular Slitted Microstrip Patch Antenna Design for Biomedical Applications, Security Purposes \& Drug Detection”, (2016).

[6] Kumud Ranjan Jha and Satish K. Sharma, "Waveguide Integrated Microstrip Patch Antenna at THz Frequency" (2014).

[7] Federal Communications Commission, "Revision of part 15 of the commission' $\mathrm{s}$ rules regarding UWB transmission systems first order and report, FCC 02-48," Tech. Rep., 
FCC, Washington, DC, USA, 2002.

[8] C. Gilmore, P. Mojabi, A. Zakaria, S. Pistorius, and J. Lovetri, "On super-resolution with an experimental microwave tomography system," IEEE Antennas and Wireless Propagation Letters, vol. 9, pp. 393-396, 2010.

[9] M. Miyakawa, T. Ishida, and M. Watanabe, "Imaging capability of an early stage breast tumor by CP-MCT.," Conf. Proc. IEEE Eng. Med. Biol. Soc., vol. 2, pp. $1427-$ 1430, 2004

[10] E. Praveen, B. Paulchamy, S. Mohanraj, and S. Mohan, "Design of1X8 Phased Array Micro-strip Patch Antennas for Biomedical Applications," no. i, pp. 68-72, 2016.

[11] S. Padhi, F. Liu, B. K. Li, N. Shuley, and S. Crozier, "On the accurate modeling of a complex antenna for breast tumor detection using a hybrid MOM/FDTD approach.," Conf. Proc. IEEE Eng. Med. Biol. Soc., vol. 2007, pp. 6637-40, 2007. 